\title{
Editorial: Renewable Energy and Oceanic Structures: Part I
}

1 José A.F.O. Correia PhD, MSc, CEng

Assistant Researcher, Department of Civil Engineering, Faculty of Engineering, University of Porto, Porto, Portugal

2 Tiago Ferradosa PhD, MSc, CEng

Assistant Researcher, Hydraulic Structures and Sea Energy Research Group, Department of Civil Engineering, Faculty of Engineering, University of Porto, Porto, Portugal

3 José Miguel Castro PhD, MSc, CEng

Assistant Professor, Department of Civil Engineering, Faculty of Engineering, University of Porto, Porto, Portugal
4 Nicholas Fantuzzi PhD, MSc, CEng

Associate Professor, DICAM Department, University of Bologna, Bologna, Italy

5 Abílio M.P. De Jesus PhD, MSc, MEng

Professor, Department of Mechanical Engineering, Faculty of Engineering, University of Porto, Porto, Portugal
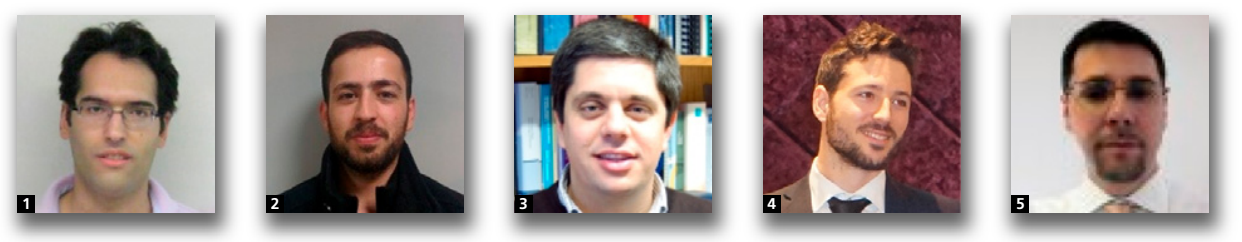

Maritime Engineering covers the investigation on safe and sustainable engineering in the salt-water environment and includes scientific and technical works regarding management, planning, design, analysis, construction, operation, maintenance and applied research related to renewable energy and oceanic engineering. In this journal are published articles from industry and academia that convey advanced research that those developing, designing or constructing schemes can begin to apply, as well as papers on good practices that others can learn from and use.

The themed issue on Renewable Energy and Oceanic Structures, Part I, was intended to be a forum of discussion of the recent advances in the domain of the structural integrity, inspection, monitoring, repair, maintenance, fatigue, fracture mechanics, structural design, stability, safety, reliability, offshore materials technologies, computational fluid dynamics, ocean renewable energy and environment. Contributions were proposed from engineers, scientists, consultants among others, in the field of ocean, offshore, polar, artic, naval, marine renewable energy, subsea, marine environmental engineering, coastal and aquaculture engineering, as well as by other specialists interested in these fields.

This issue of ICE's Maritime Engineering journal reflects on the following topics: structural integrity of offshore structures; dynamic response of pipelines under flexural loads; and finally, assessment of wave energy resources.

The first paper (Rege and Pavlou, 2019) presents a procedure for modelling the stop hole induced fatigue crack growth delay for a crack propagating under mixed-mode I + II conditions. This procedure combines the $S-N$ curve for fatigue crack initiation and the Paris law for fatigue crack propagation. The procedure is implemented to evaluate the structural integrity of a plate with circular hole used in offshore structures applications.

In the second paper (Pavlou and Correia, 2019) proposed an exact solution for pipeline response under transient and harmonic loads. In this way, the authors modelled the fluidpipe interaction under transient loading conditions through the equilibrium and motion partial differential equations. A system of 8 first-order coupled partial differential equations and the integral transforms are used for achieving an analytical solution. Additionally, the methodology is based on double integral transforms. The methodology proposed is applied for pipelines subjected to impact and harmonic loads, and their results are provided.

The paper by Jiang et al. (2019) presents an assessment of wave energy resources in the South China Sea and prepares the basis of plans for developing and using wave energy at the referred region. Additionally, a guidance to site wave power stations as well as the design criteria for wave energy convertors are provided. According to this study, the results showed that areas with abundant and stable exploitable wave energy in the South China Sea, mainly between the Luzon Strait and the southeast of the Indo-China Peninsula, the annual average wave energy fluxes ranged from 10 to $18 \mathrm{~kW} / \mathrm{m}$. In this way, the authors have concluded that the wave energy resources and 
the frequency of high sea states need to be considered when choosing sites for wave energy farms.

\section{REFERENCES}

Jiang B, Wu G, Ding J, Ma C, Fang Y and Wang X (2019) Assessment of the wave energy resource in the South China Sea. Proceedings of the Institution of Civil Engineers - Maritime Engineering, 172(1): 23-33, https://doi.org/10.1680/jmaen.2018.29.
Pavlou DG and Correia JA (2019) Dynamic response of pipelines under impact and harmonic loading. Proceedings of the Institution of Civil Engineers - Maritime Engineering, 172(1): 15-22, https://doi.org/10.1680/jmaen.2019.2.

Rege K and Pavlou DG (2019) Effect of stop holes on structural integrity of offshore structures: a numerical model. Proceedings of the Institution of Civil Engineers Maritime Engineering, 172(1): 3-14, https://doi.org/10.1680/ jmaen.2018.34. 